\title{
PULSATILE LH SECRETION IN WOMEN WITH PREMENSTRUAL SYNDROME (PMS): EVIDENCE FOR NORMAL NEUROREGULATION OF THE MENSTRUAL CYCLE
}

\author{
NANCY E. ReAmE ${ }^{1}$, John C. MARshall ${ }^{2}$, and Robert P. KelCH ${ }^{3}$ \\ ${ }^{1}$ School of Nursing and Division of Endocrinology and Metabolism, Departments of 2Internal Medicine \\ and ${ }^{3}$ Pediatrics, University of Michigan Medical Center, Ann Arbor, Michigan, U.S.A.
}

(Received 31 January 1991; in final form 24 July 1991)

\begin{abstract}
SUMMARY
The premenstrual syndrome (PMS) has been proposed to result from excessive exposure to and/or withdrawal of brain opioid activity during the luteal phase. Because hypothalamic opioids are believed to modulate GnRH secretion, in part under the influence of ovarian steroids, we performed longitudinal studies of gonadotropin and ovarian steroid secretion across ovulatory, symptomatic cycles of 17 PMS patients and 8 normal volunteers. Pulsatile LH secretion was measured every $10 \mathrm{~min}$ for $8 \mathrm{hr}$ at times when central opioid activity was expected to be low (early follicular phase), high (mid-luteal phase; ML), and declining (late luteal phase). In both subject groups, a cycle-phase effect was observed for LH pulse frequency $(p=<0.001)$ and amplitude $(p=0.002)$, and for the transverse mean concentrations of LH $(p=0.05)$, FSH $(p<=0.001)$, estradiol $\left(\mathrm{E}_{2}\right)$ $(p=<0.001)$ and progesterone (P) $(p=<0.001)$. ML $\mathrm{P}$ secretion in PMS patients was pulsatile, and mean concentrations (over 30-60 min) were similar to those of normal controls. The changes in pulsatile LH secretion across the cycle were not different in the PMS patients compared to the normal women, though mean FSH in the ML phase was higher in the PMS group ( $p=<0.05)$. The similar changes in luteal LH pulse frequency fail to provide evidence that GnRH secretion is impaired, thus challenging the view that the neuroregulation of the menstrual cycle in women with PMS is markedly altered.
\end{abstract}

\section{INTRODUCTION}

THE MECHANISMS INVOLVED in producing the complex of symptoms collectively termed the premenstrual syndrome (PMS) are unknown. The failure to identify gross aberrations in plasma concentrations of the reproductive hormones has led investigators to search for a common link between the dynamic neuroendocrine secretory events that characterize the menstrual cycle and central mechanisms regulating behavior and mood states. It has been proposed that premenstrual symptoms occur in response to the cyclic rise and fall in hypothalamic opioid activity believed to modulate the pulsatile release of gonadotropin-releasing hormone (GnRH) and, in turn, luteinizing hormone (LH), as a result of the characteristic changes in the ovarian production of estrogen and progesterone (P) (Halbreich \& Endicott, 1981; Reid \& Yen, 1981). Advocates propose that the withdrawal of high opioid activity prior to menses disinhibits

Address correspondence and reprint requests to: Dr. Nancy E. Reame, The University of Michigan, Women's Health Research Project, School of Nursing, 400 North Ingalls, Ann Arbor MI 48109-0482, USA. 
opioid-sensitive neurons, resulting in such dysphoric symptoms as irritability, insomnia, food cravings, anxiety, and pain sensitivity (Chuong et al., 1988; Facchinetti et al., 1988; 1990). LH pulse frequency in the mid-luteal (ML) phase has been reported to be faster in PMS patients, despite similar concentrations of P compared to normal volunteers (Facchinetti et al., 1990). This finding, as well as earlier evidence that LH responsiveness to the opiate antagonist, naloxone, was blunted in PMS patients (Facchinetti et al., 1988), prompted these investigators to propose that PMS was a central disorder, due to a hypothalamic impairment of the opioid inhibition normally present at this time in the cycle. Differences in LH pulse frequency and amplitude between the patient and control groups in the later study (Facchinetti et al., 1990) were small, however, and secretory characteristics were within the normal range of variability previously reported for normal, asymptomatic women (Reame et al., 1984). In addition, these investigators noted that the presence of secondary psychiatric disorders in some of the PMS subjects may have confounded their results.

Given the recognized role of endogenous opioids in mediating the luteal slowing of GnRH/LH pulsatile secretion (Quigley \& Yen, 1980; van Vugt et al., 1984), and to further characterize the neuroreproductive axis in PMS, we conducted a longitudinal assessment of pulsatile gonadotropin and ovarian steroid secretion in women with PMS at times in the menstrual cycle previously shown to be differentially influenced by central opioid activity (Quigley \& Yen, 1980; Wardlaw et al., 1982).

\section{SUBJECTS AND METHODS}

\section{Subjects}

Twenty women between the ages of 26 and $39 \mathrm{yr}$ (mean \pm SEM $=32.9 \pm 4 \mathrm{yr}$ ) were recruited from a pool of 172 gynecologic patients diagnosed with PMS as defined by the National Institute of Mental Health guidelines (Blume, 1983). Subjects were referred by their clinician after symptom assessment but prior to the initiation of therapy. The diagnosis of PMS was based on prospective confirmation of the presence of luteal phase emotional and physical symptoms which resolved before the end of menses and occurred in at least two subsequent cycles. The symptom rating scales used by the referring physicians included the Self Rating Scale for Premenstrual Tension Syndrome (Steiner et al., 1980), the Prospective Record of the Impact and Severity of Menstrual Symptomatology (PRISM) calendar (Reid, 1985), and a visual linear analogue scale (Casper \& Powell, 1986).

Selection criteria included a history of regular menses, normal body weight $( \pm 15 \%$ ideal body weight [IBW]) and 6 mo or more of cyclic distress resulting in significant disruption of personal or professional functioning. The mean duration of PMS symptoms was $5.2 \pm 0.4 \mathrm{yr}$ (range $3-9 \mathrm{yr}$ ). All subjects were free of demonstrable medical illness and had not been taking medications, including oral contraceptives, during the previous 6 mo. There was no evidence of psychiatric dysfunction as measured by the SCL-90 Questionnaire (Derogatis et al., 1976), the Center for Epidemiologic Studies Depression Scale (Radloff, 1977), or psychiatric interview conducted during the follicular phase of the cycle. There was no hirsutism or clinical evidence of thyroid disease on physical examination, and plasma prolactin, testosterone, dihydroepiandrosterone sulphate, and beta human chorionic gonadotropin were normal at the time of study.

\section{Protocol}

The studies were approved by the Institutional Review Board and were performed in the Clinical Research Center of the University of Michigan Hospital after written informed consent had been obtained.

LH pulsatility was assessed longitudinally at three time points in the menstrual cycle which have been previously well-characterized in normal women, and when endogenous opioid activity is presumed to be minimal (early follicular phase; EF), maximal ML phase and diminished (late luteal phase; LL). Studies were conducted on days 5-6 after menses onset (EF), days 5-9 post-LH surge (ML), and days $11-15$ post-LH surge (LL). In all cases, the ML and LL studies were at least 5 days apart. During each 8 -hr study $(0900 \mathrm{~h}-$ $1700 \mathrm{~h}$ ), blood samples were obtained through an indwelling intravenous forearm catheter every $10 \mathrm{~min}$ for 
measurement of LH, every $60 \mathrm{~min}$ for FSH, every $30 \mathrm{~min}$ for $\mathrm{P}$ in the ML and $60 \mathrm{~min}$ in the LL, and every $2 \mathrm{hr}$ for estradiol $\left(E_{2}\right)$. The timing of the LH surge was estimated by the increase in urinary LH determined with a home, enzyme-linked immunosorbent assay kit (First Response ${ }^{\mathrm{TM}}$, Tambrands, Lake Success, NY). Blood also was obtained for determination of $E_{2}$ and P every other day between the ML and LL study days.

\section{Symptom Assessment}

To confirm menstrual symptom characteristics during the study cycle, subjects rated themselves on the incidence and severity of 40 symptoms commonly associated with menstrual cycle distress using a check list developed by Woods (1987), based on the work of Moos (1968), Haskett et al. (1980), and Halbreich et al. (1982). Beginning 2 wk prior to the onset of the study cycle, women rated the items on a scale of 0 (not present) to 4 (extreme) at the end of each day. The 40 menstrual-related items were embedded alphabetically within a larger list of 57 negative and positive symptoms (e.g., blurred vision, general well-being). After data collection, the daily diaries were synchronized with menstrual cycle days. The three highest daily symptom scores of the postmenstrual week (days 4 through 10 after menses onset) and the subsequent premenstrual week (days 7 through 1 premenses) were used to compute a menstrual phase mean score (Woods, 1987).

\section{Control Studies in Normal Volunteers}

Eight normal volunteers prospectively monitored body symptoms across a menstrual cycle during which blood-sampling studies were performed in the EF and ML. In four subjects, a third study was conducted in the LL. Criteria for subject selection included: 21-39 yr of age, regular cycles of 25-32 days, normal body weight ( $\pm 15 \%$ IBW), postpartum and nonlactating for at least 6 mo, no medication use including oral contraceptives for the previous $6 \mathrm{mo}$, no history of medical treatment for endocrine or gynecologic disease including debilitating premenstrual/menstrual complaints, and normal findings on physical examination.

\section{Assays}

Plasma LH and FSH were measured by (RIA) methods previously reported (Midgley, 1966; 1967). Plasma $E_{2}$ (assay sensitivity: $5 \mathrm{pg} / \mathrm{ml}, 18 \mathrm{pmol} / 1$ ) and $P$ (assay sensitivity: $0.2 \mathrm{ng} / \mathrm{ml}, 0.64 \mathrm{nmol} / \mathrm{l}$ ) were measured with RIA kits (Diagnostic Products, Los Angeles, CA; Radioassay Systems Laboratories, Carson, CA). Gonadotropin concentrations are reported as IU/l of the second IRP human menopausal gonadotropin after conversion from LER 907, which was used as the assay standard. For the LH and FSH assays, the assay sensitivities were 1.0 and $1.4 \mathrm{IU} / \mathrm{l}$, respectively, and the interassay coefficient of variation (CV) was $11 \%$. For $\mathrm{LH}$ and FSH, the intraassay CV was inversely proportional to the measured amount, averaging $20 \%, 9.5 \%$ and $6.6 \%$ for concentrations of $2.5,7.5$ and $15 \mathrm{IU} / \mathrm{l}$, respectively. For analysis, values below assay sensitivity were assigned a value of the assay sensitivity.

\section{LH Pulse Analysis}

The number of LH pulses occurring in each 8-hr sampling period was determined as previously described (Reame et al., 1984; Hale et al., 1988). A minimal detectable increment (MDI) was determined for each 8-hr sampling period. The MDI was calculated as the product of the mean LH concentration and three times the intraassay coefficient of variation (CV) of replicate samples for each sampling period (MDI = mean $\mathrm{LH} \times \mathrm{CV} \times$ 3 ). If the calculated MDI was less than the assay sensitivity for that period, the value of the assay sensitivity was used. An LH pulse was defined as an increase from nadir to peak greater than or equal to the MDI, occurring within $40 \mathrm{~min}$. The $\mathrm{LH}$ pulse amplitude was calculated as the difference between the peak value and the preceding nadir value. Only those pulses with amplitudes exceeding the mean assay sensitivity (1.0 IU/l) were accepted. The maximum false positive rate was less than 1-2 pulses/100 comparisons. Missing values comprised less than $0.5 \%$ of the total samples and were left blank. This method of pulse analysis has been compared in previous studies of normal women to the computerized peak detection program, Detect, version 4.8 (Oerter $e t$ al., 1986), and shown to provide similar estimates of pulse frequency (Nippoldt $e t a l ., 1989$ ).

\section{Statistical Analysis}

Data are presented as means \pm SEM. Hormone values are expressed as $\mathrm{IU} / 1$ for $\mathrm{LH}$ and $\mathrm{FSH}, \mathrm{nmol} / \mathrm{l}$ for $\mathrm{P}$, and $\mathrm{pmol} / 1$ for $\mathrm{E}_{2}(1 \mathrm{ng}=3.18 \mathrm{nmol} ; 1 \mathrm{pg}=3.6 \mathrm{pmol})$. The distribution of hormone values was assessed for normality. In some cases, a log transformation was needed due to skewed distribution; however, transformation did not change any of the results, and the transformed data are not reported. Differences in mean hormone 
secretion characteristics across the three cycle phases in the patient and control groups were determined by analysis of variance and multiple comparison procedures (Fisher's least significant difference or Sheffe) if the overall $\mathrm{F}$ ratio was significant $(p=<0.05)$.

\section{RESULTS}

\section{Menstrual Cycle Characteristics}

Study cycles from all subjects were judged to be ovulatory as evidenced by plasma $P$ values of $>15 \mathrm{nmol} / 1(5 \mathrm{ng} / \mathrm{ml})$ on at least two occasions in the ML phase. In three subjects in the PMS group, peak plasma P levels were not observed until 11 to 14 days after the estimated LH surge, and cycle lengths were 22,37 and 40 days. Post-study cycles were 26, 28 and 25 days in length, respectively. Because these observations suggested atypical ovulatory cycles, the data from these individuals were excluded from analysis, resulting in a final sample size of 17 in the PMS group. None of the normal volunteers experienced an atypical cycle during the study, although it has been our experience over the last $10 \mathrm{yr}$ that abnormal cycles occur in approximately $10 \%$ of subjects who undergo these intensive studies.

\section{Symptom Characteristics During Study}

In both the postmenstrual and the premenstrual weeks of the study cycle, the volunteer group demonstrated a lower mean symptom score $(p=0.001$, ANOVA) than the patient group. Mean age and cycle length were similar (Table I). Since underlying psychiatric disorders had been ruled out during the diagnostic evaluation, the higher "baseline" scores of the postmenstrual week more likely reflected the chronic nature and severity of the menstrual health problem. Little is known about how PMS symptom patterns change over time, especially in women who fail to benefit from standard treatment approaches. It has been proposed that for women suffering from severe, long-term premenstrual symptoms, the "symptom-free" interval associated with the follicular phase is compromised by feelings of guilt and depression for neglect of family and professional responsibilities (Reid, 1985).

The PMS group showed an almost three-fold increase in mean symptom scores in the subse-

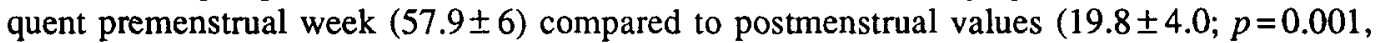
ANOVA). The scores of most PMS subjects greatly exceeded the minimum $30 \%$ increase (\% mean increase $\pm S E M=525 \pm 181 \%$; range $=36 \%$ to $2250 \%$ ) required to meet the definition for PMS adopted by the National Institutes of Mental Health PMS Research Workshop Workgroup (Blume, 1983).

TABle I. Clinical CHARACTERISTICS AND MENSTRUAL SYMPTOM SCORES (MEAN \pm SEM) AT THE TIME OF STUDY FOR PMS PATIENTS AND NORMAL VOLUNTEERS (NV)

\begin{tabular}{lcccrr}
\hline Group & Age & $\begin{array}{c}\text { Study Cycle } \\
\text { Length (days) }\end{array}$ & \multicolumn{2}{c}{ Symptom Score } \\
Post-Menses & Pre-Menses \\
\hline PMS & $\mathbf{n}$ & $32.3 \pm 0.8$ & $27.7 \pm 0.7$ & $19.8 \pm 4.0$ & $57.9 \pm 6.0$ \\
NV & 8 & $32.0 \pm 0.2$ & $27.1 \pm 1.0$ & $7.5 \pm 3.0$ & $8.9 \pm 3.0$ \\
\hline
\end{tabular}

Fost-vs. Pre- (PMS): $p=0.001$; PMS vs. NV: $p=0.001$. 


\section{Gonadotropin and Ovarian Steroid Secretion in PMS Patients}

By ANOVA, a significant luteal phase change occurred in mean LH concentration, LH pulse frequency, LH pulse amplitude, mean FSH, and mean levels of $E_{2}$ and $P$ (Table II). LH pulse frequency slowed from an EF frequency of $7.5 \pm 0.6$ pulses $/ 8 \mathrm{hr}$ to $4.0 \pm 0.3 \mathrm{pulses} / 8 \mathrm{hr}$ in the ML, and pulse amplitude increased from $2.2 \pm 0.2 \mathrm{IU} / 1$ (EF) to $4.6 \pm 0.7 \mathrm{IU} / 1$ (ML). Mean FSH was lower in the ML when ovarian steroids were elevated. Figure 1 presents serial measures of plasma gonadotropins and ovarian steroids in two subjects with PMS showing representative changes in pulsatile LH secretion between the follicular and luteal studies.

During the ML studies, plasma P was measured every $30 \mathrm{~min}$ and assessed for pulsatile secretion. By criteria previously used in normal women (a secretory pulse was defined as an increase of five times the SEM of the mean within $120 \mathrm{~min}$ of the previous nadir [Healy et al., $1984])$, secretory fluctuations of $12.7 \pm 2.0 \mathrm{nmol} / 1(4.0 \pm 0.7 \mathrm{ng} / \mathrm{ml})$ amplitude occurred at a mean frequency of $2.4 \pm 0.4$ pulses $/ 8 \mathrm{hr}$. Figure 2 shows ML $P$ secretion in three subjects with varying severity of PMS symptoms. During the ML studies, plasma $P$ was close to the group mean level (30.9 $\pm 4.0 \mathrm{nmol} / \mathrm{l} ; 9.5 \pm 1 \mathrm{ng} / \mathrm{ml}$ ) in PMS subjects with both high (Subject 5) and low (Subject 6) symptom severity scores. In Subject 2, low symptom severity scores were associated with plasma $P$ levels in the high-normal range, but LH pulse frequency was not excessively slowed in this individual ( 5 pulses $/ 8 \mathrm{hr}$ ). Overall, there was no significant correlation between MLP concentrations and premenstrual symptom scores.

\section{Comparison of Data in PMS Subjects and Normal Volunteers}

Plasma ovarian steroids were not statistically different between groups on the three study days, although in the LL, a lower mean value for both $E_{2}$ and $P$ in the normal volunteers was apparent. The four normal volunteers were all evaluated on the day prior to menses, resulting

TABle II. Plasma GONAdOTROPIN AND OVARIAN STEROIDS IN PMS SUbJeCtS AND NORMAL VOLUNTEERS AT SIMILAR PHASES OF THE MENSTRUAL CYCLE (MEAN \pm SEM)

\begin{tabular}{lcccc}
\hline & & \multicolumn{3}{c}{ Cycle Phase (Days \pm LH Surge) } \\
& Group & EF (-10 to -7) & ML (+5 to +9) & LL (+11 to +15) \\
\hline Mean LH & PMS & $6.5 \pm 0.6^{*}$ & $5.1 \pm 0.6$ & $5.5 \pm 0.5$ \\
(IU/1) & NV & $5.8 \pm 0.7^{* *}$ & $3.8 \pm 0.3$ & $5.1 \pm 0.5$ \\
LH pulse frequency & PMS & $7.5 \pm 0.6^{* *}$ & $4.0 \pm 0.3$ & $5.2 \pm 0.5$ \\
(pulses/8 hr) & NV & $5.9 \pm 1.0^{* *}$ & $2.8 \pm 0.5$ & $6.0 \pm 0.7$ \\
LH pulse amplitude & PMS & $2.2 \pm 0.2^{* * *}$ & $4.6 \pm 0.7$ & $3.1 \pm 0.3$ \\
(IU/1) & NV & $2.2 \pm 0.2^{* * *}$ & $4.0 \pm 1.1$ & $3.1 \pm 0.5$ \\
Mean P & PMS & $0.6 \pm 0^{* *}$ & $30.9 \pm 4.0$ & $8 \pm 2$ \\
(nmol/1) & NV & $0.6 \pm 0^{* *}$ & $27.7 \pm 3.0$ & $1.3 \pm 0.3$ \\
Mean E 2 & PMS & $166 \pm 15^{* *}$ & $290 \pm 26$ & $184 \pm 26$ \\
(pmol/1) & NV & $103 \pm 22^{* *}$ & $334 \pm 40$ & $73 \pm 11$ \\
Mean FSH & PMS & $6.7 \pm 0.6^{* *}$ & $4.6 \pm 0.6 \dagger$ & $5.4 \pm 0.6$ \\
(IU/1) & NV & $5.1 \pm 0.5^{* *}$ & $1.7 \pm 0.3$ & $4.1 \pm 0.7$ \\
\hline
\end{tabular}

EF = early follicular, $\mathrm{ML}=$ mid-luteal, $\mathrm{LL}=$ late luteal.

PMS = premenstrual syndrome patients $(n=17) ; \mathrm{NV}=$ normal volunteers $(n=8$ at $\mathrm{EF}$ and $\mathrm{ML}, \mathrm{n}=4$ at $\mathrm{LL}$ )

${ }^{*}$ EF vs. ML, $p=0.05 \quad{ }^{*}$ EF vs. ML, $p=<0.001 \quad * * *$ EF vs. ML, $p=0.002 \quad \dagger_{\mathrm{PMS}}$ vs. NV, $p=<0.05$ 

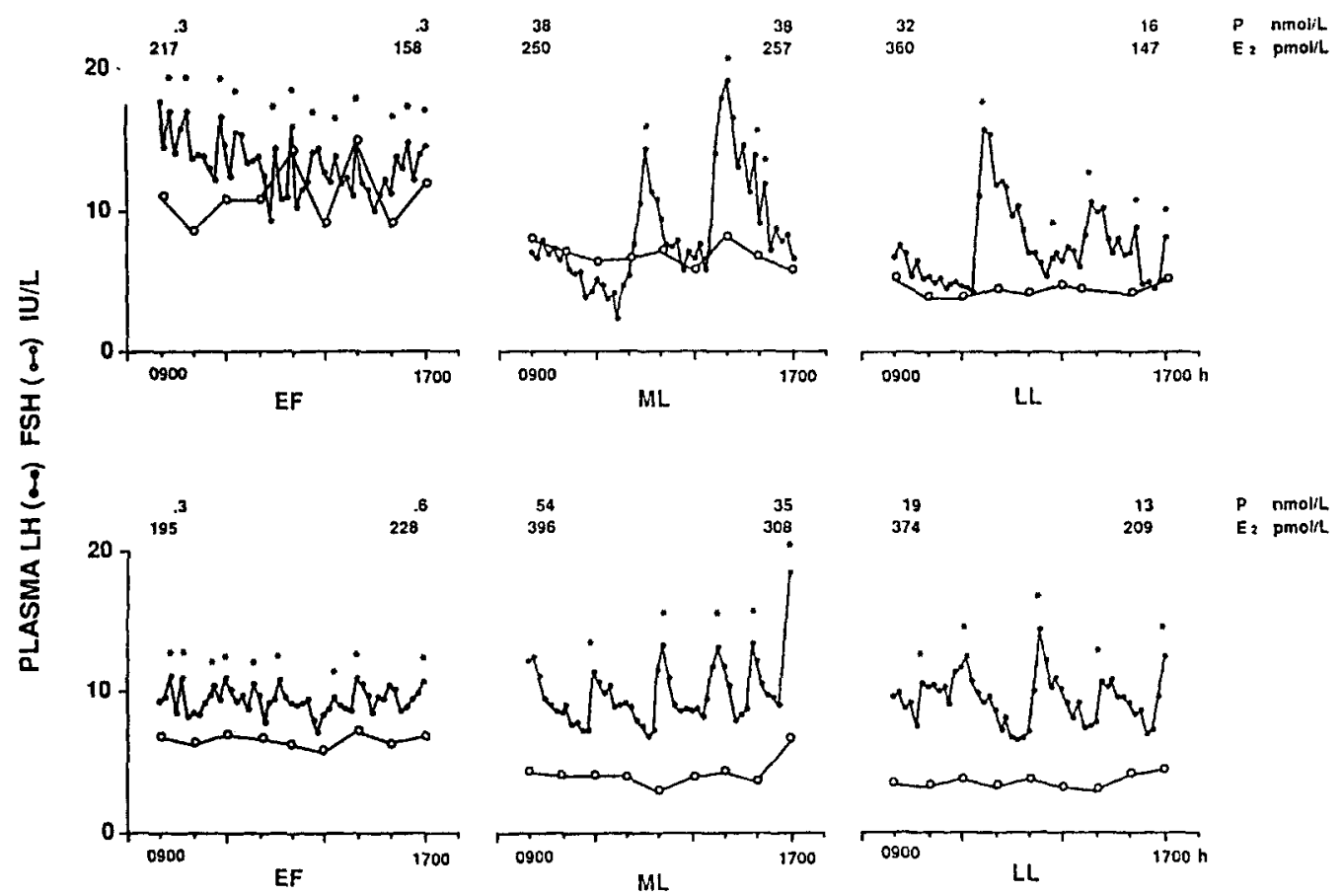

Fig. 1: Plasma gonadotropins and ovarian steroids during 8-hr rapld-sampling studies in the EF, ML, and LL phases of the menstrual cycle in two subjects with PMS. $*=\mathrm{LH}$ pulse. $\mathrm{E}_{2}$ and $\mathrm{P}$ values shown are for the beginning and end of the rapid-sampling periods.
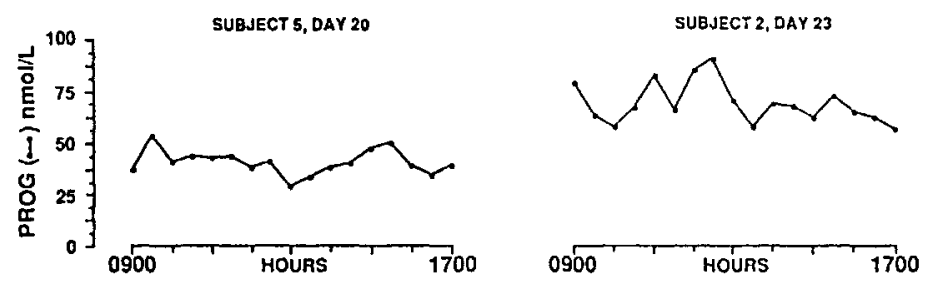

SUBJECT 6, DAY 21
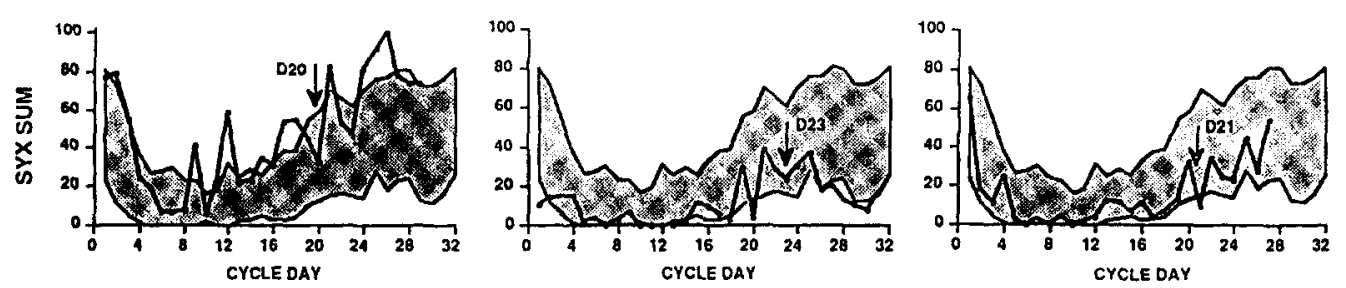

FIG. 2: Pulsatile secretion of $P$ (top panel) during the ML studies in PMS patients with varying severity of symptoms (Subjects 5,2, and 6). The bottom panel depicts dally symptom scores (syx sum; solid line) of each subject across the cycle compared to the scores (mean \pm SD) for the 20 patients with PMS. For each patient the symptom scores are shown for the entire cycle, and the actual ML study day is indicated by an arrow. 
in lower values compared to the PMS group, in whom LL studies were performed on average 2 days prior to menses. Single measures of $E_{2}$ and $P$ taken between the ML and LL studies (days 9 and 11 post-LH surge) revealed no difference in the rate of decline in corpus luteum function for the two groups.

Mean plasma FSH was different in the PMS and control groups ( $p=0.002$; ANOVA), in that mean FSH was higher in the PMS patients in the ML studies ( $p=<0.05$, Fisher's multiple comparison). No significant differences in pulsatile LH secretory characteristics were found between PMS patients and normal volunteers across the three study days.

\section{DISCUSSION}

We studied changes in pulsatile LH secretion in women with PMS to detect peripheral evidence of alterations in the transient increase and withdrawal of endogenous opioid action on GnRH secretion during ovulatory, symptomatic cycles. We chose three different "windows" in the menstrual cycle which have been characterized previously in relation to ovarian steroids, gonadotropin secretion, menstrual symptomatology, and presumed opioid activity. The current view of the hormonal interrelationships in the normal luteal phase is that $P$ in the presence of $E_{2}$ acts on the hypothalamus to transiently increase opioid activity, thus inhibiting the frequency of pulsatile GnRH secretion and in turn the pulsatile release of LH (Yen et al., 1972; Backstrom et al., 1982; Filicori et al., 1984; Soules et al., 1984). With the fall in $\mathrm{E}_{2}$ and $\mathrm{P}$ secretion from the aging corpus luteum, opioid exposure is withdrawn, allowing GnRH pulsatile secretion to increase in the days preceding menses (Marshall \& Kelch, 1986). Thus, assessment of LH pulse frequency in women has been used to infer changes in GnRH secretion and may allow a gross estimation of hypothalamic opioid influence when performed in the presence of a welldefined ovarian steroid milieu.

A more direct measure of hypothalamic opioid activity is $\mathrm{LH}$ responsiveness to naloxone infusion, which was not assessed in the present study. We chose to characterize the phasic changes in endogenous pulsatile LH secretion without the potential effects of an agent known to influence LH pulse characteristics and possibly PMS symptoms. Therapeutic effects of naltrexone, the orally active opiate antagonist, have been observed in a placebo-controlled, doubleblinded study of PMS patients (Chuong et al., 1988).

We found no evidence of excessive slowing (ML study) or acceleration (LL study) of LH pulse frequency which might have been predicted if neuroendocrine regulatory mechanisms were dysfunctional. Given the degree of intragroup variability in LH pulse frequency, we were unable to detect small to modest differences in the regulation of GnRH secretion in the PMS patients. A true difference of this questionable magnitude seems an unlikely mediator of PMS symptomatology, however, and the pattern of pulsatile LH secretion in PMS patients was similar to that described in previous studies of normal volunteers (Santen \& Bardin, 1973; Backstrom et al., 1982; Filicori et al., 1984; Reame et al., 1984). Taken together, these results provide evidence that the symptoms of PMS can occur in the absence of marked abnormalities in the neuroreproductive axis and challenge the view that opioid inhibition of GnRH secretion is impaired. These findings, however, do not rule out aberrations in other steroid-mediated opioid action external to the hypothalamus that could play a role in the emotional and cognitive symptoms associated with this disorder.

Further studies are necessary to confirm our finding of higher FSH secretion in PMS patients, but it would seem to suggest a lowered sensitivity of FSH to ovarian feedback regulation. Interestingly, this effect was most pronounced during the ML phase, a time when inhibin 
is believed to act in concert with $\mathrm{E}_{2}$ to inhibit FSH secretion, and may suggest an area for future study. To what extent a dampening of the ovarian feedback regulation of FSH release might be related to the cyclic psychologic and behavioral disturbances of PMS is purely speculative at present.

P secretion, when measured every $30 \mathrm{~min}$ in the ML phase, was observed to be pulsatile in PMS patients and similar to that reported for normal women (Filicori et al., 1984). This finding further strengthens evidence from studies of daily hormone measures that the ability to secrete ovulatory levels of ovarian steroids is not compromised in PMS (Rubinow et al., 1988). More over, our finding that peripheral plasma $P$ concentrations bear no relationship to PMS symptom severity fails to support the use of ovarian steroids in the treatment of this disorder.

Acknowledgements: Supported by NIH Grants R01-NU-01373-04, R01-HD-1600-05, 5-P30-HD18258, and Clinical Research Center grant 5M01-RR42. We are grateful to Roger Haskett, M.D., for providing psychiatric screening of selected subjects, and we acknowledge the expert technical assistance of Dr. M. Yu, Ms. Lyn Conlon, Ms. C. Zawacki, Ms. K. Kersey, Mr. S. Schmaltz, Ms. S. Ostrowski, the excellent secretarial support of Ms. S. Frank, and the nursing staff of the Clinical Research Center. The urinary LH kits were generously supplied by Tambrands, Inc.

\section{REFERENCES}

Backstrom CT, McNeilly AS, Leask RM, Baird DT (1982) Pulsatile secretion of LH, FSH, prolactin, oestradiol and progesterone during the human menstrual cycle. Clin Endocrinol 17: 29-42.

Blume E (1983) Methodological differences plague PMS research. JAMA 249: 2866.

Casper RF, Powell AM (1986) Premenstrual syndrome: documentation by a linear analog scale compared with two descriptive scales. Am J Obstet Gynec 155: 862-867.

Chuong CJ, Coulam CB, Bergstrahl EJ, O'Fallon WM, Steinmetz GI (1988) Clinical trial of naltrexone in premenstrual syndrome. Obstet Gynecol 72: 332-336.

Derogatis L, Rickels K, Roch A (1976) The SCL-90 and the MMPI: a step in the validation of a new self-report scale. Brit J Psychiatry 128: 280-289.

Facchinetti F, Martignoni E, Sola D, Petraglia F, Nappi G, Genazzani AR (1988) Transient failure of central opioid tonus and premenstrual symptoms. J Reprod Med 33: 633-638.

Facchinetti F, Genazzani AD, Martignoni E, Fioroni L, Sances G, Genazzani AR (1990) Neuroendocrine correlates of premenstrual syndrome: changes in the pulsatile pattern of plasma LH. Psychoneuroendocrinology 15: $269-277$.

Filicori M, Butler JP, Crowley WF (1984) Neuroendocrine regulation of the corpus luteum in the human: evidence for pulsatile progesterone secretion. J Clin Invest 73: 1638-1647.

Halbreich U, Endicott J (1981) Possible involvement of endorphin withdrawal or imbalance in specific premenstrual syndromes and post partum depression. Med Hypotheses 7: 1045-1058.

Halbreich U, Endicott J, Schach D, Nee J (1982) The diversity of premenstrual changes as reflected in the premenstrual assessment form. Acta Psychiatr Scand 65: 46-65.

Hale PM, Khoury S, Foster CM, Beitins IZ, Hopwood NJ, Marshall JC, Kelch RP (1988) Increased LH pulse frequency during sleep in early pubertal boys - effects of testosterone infusion. J Clin Endocrinol Metab 66: 785-791.

Haskett R, Steiner M, Osmun J, Carroll B (1980) Severe premenstrual tension: delineation of the syndrome. Biol Psychiat 15: 121-139.

Healy DL, Schenken RS, Lynch A, Williams RF, Hodgen GD (1984) Pulsatile progesterone secretion: its relevance to clinical evaluation of corpus luteum function. Fertil Steril 41: 114-121.

Marshall JC, Kelch RP (1986) Gonadotropin-releasing hormone: role of pulsatile secretion in the regulation of reproduction. New Eng J Med 315: 1459-1468.

Midgley AR (1966) Radioimmunoassay: a method for human chorionic gonadotropin and human luteinizing hormone. Endocrinology 79: 10-18. 
Midgley AR (1967) Radioimmunoassay for human follicle stimulating hormone. J Clin Endocrinol Metab 27: 295-299.

Moos RH (1968) The development of a menstrual distress questionnaire. Psychosom Med 30: 853-867.

Nippoldt TB, Reame NE, Kelch RP, Marshall JC (1989) The roles of estradiol and progesterone in decreasing luteinizing hormone pulse frequency in the luteal phase of the menstrual cycle. J Clin Endocrinol Metab 69: 67-76.

Oerter KE, Gvardabasso V, Rodbard D (1986) Detection and characterization of peaks and estimation of instantaneous secretory rate for episodal pulsatile hormone secretion. Comput Biomed Res 19: 170-191.

Quigley ME, Yen SSC (1980) The role of endogenous opiates in LH secretion during the menstrual cycle. $J$ Clin Endocrinol Metab 51: 179 -181.

Radloff L (1977) The CES-D scale: a self report depression scale for research in the general population. Appl Psych Measurement 1: 385.

Reame NE, Sauder SE, Kelch RP, Marshall JC (1984) Pulsatile gonadotropin secretion during the human menstrual cycle: evidence for altered frequency of GnRH secretion. J Clin Endocrinol Metab 59: 328-337.

Reid RL (1985) Premenstrual syndrome. Curr Prob Obstet Gynecol Fertil 8: 43-61.

Reid RL, Yen SSC (1981) Premenstrual syndrome. Am J Obstet Gynecol 139: 85-104.

Rubinow DR, Hoban MC, Grover GN, Galloway DS, Roy-Byrne P, Andersen R, Merriam GR (1988) Changes in plasma hormones across the menstrual cycle in patients with menstrually related mood disorder and in control subjects. Am J Obstet Gynecol 158: 5-11.

Santen RJ, Bardin CW (1973) Episodic luteinizing hormone secretion in man: pulse analysis, interpretation, physiologic mechanisms. J Clin Invest 52: 2617-2628.

Soules MR, Steiner RA, Clifton DK, Cohen NL, Aksel S, Bremner WJ (1984) Progesterone modulation of pulsatile luteinizing hormone secretion in normal women. J Clin Endocrinol Metab 58: 378-383.

Steiner M, Haskett RF, Carroll BJ (1980) Premenstrual tension syndrome: the development of research diagnostic criteria, and new rating scales. Acta Psychiatr Scand 62: 177.

van Vugt DA, Lam NY, Ferin M (1984) Reduced frequency of pulsatile luteinizing hormone secretion in the luteal phase of the Rhesus monkey. Involvement of endogenous opiates. Endocrinology 115: 1095-1099.

Wardlaw SL, Wehrenberg WB, Ferin M, Antunes JL, Frantz AC (1982) Effect of sex steroids on $\beta$-endorphin in hypophyseal portal blood. J Clin Endocrinol Metab 55: 877-881.

Woods NF (1987) Premenstrual symptoms: another look. Public Health Rep Suppl July-Aug: 106-112.

Yen SSC, Tsai CC, Naftolin F, Vandenberg G, Ajabor L (1972) Pulsatile patterns of gonadotropin release in subjects with and without ovarian function. J Clin Endocrinol Metab 34: 671-675. 